\title{
D-Effect Algebra Can Be Made into a D-Total Algebra
}

\author{
Ahmed Allam ${ }^{1}$, Nabila Mikhaeel ${ }^{1}$, Huda Merdach ${ }^{2}$ \\ ${ }^{1}$ Department of Mathematics, Faculty of Science, Assiut University, Assiut, Egypt \\ ${ }^{2}$ Department of Mathematics, Faculty of Science, Damietta University, Damietta, Egypt
}

Email address:

merdach.2.11@gmail.com (H. Merdach), huda_merdach@du.edu.eg (H. Merdach)

To cite this article:

Ahmed Allam, Nabila Mikhaeel, Huda Merdach. D-Effect Algebra Can Be Made into a D-Total Algebra. Mathematics Letters. Vol. 3, No. 6, 2017, pp. 71-76. doi: 10.11648/j.ml.20170306.13

Received: April 11, 2017; Accepted: May 20, 2017; Published: November 28, 2017

\begin{abstract}
In this paper we prove that every D-effect algebra $(\mathrm{E}, \Delta, 0,1)$ can be made into a D-total algebra $(\mathrm{E}, \Delta, \neg, 1)$ in such a way that two elements are compatible in $(\mathrm{E}, \Delta, 0,1)$ if and only if they commute in $(\mathrm{E}, \Delta, \neg, 1)$ where $\mathrm{x} \Delta \mathrm{y}=\left(\mathrm{x}^{\prime}+\mathrm{y}^{\prime}\right)^{\prime}$.
\end{abstract}

Keywords: D-Basic Algebra, Weak D-Basic Algebra, Antitone Involution, D-Effect Algebra, D-Total Algebra

\section{Introduction}

Chajda, I., Halas, R., Kuhr, J. (2009) introduced similar results for general effect algebras in the context of commutative directoids; they proved that every effect algebra $(\mathrm{E},+, 0,1)$ can be made into a total algebra $(\mathrm{E}, \oplus, \neg, 0)$ in such a way that two elements are compatible in $(\mathrm{E},+, 0,1)$ if and only if they commute in $(\mathrm{E}, \oplus, \neg, 0)$.

In the present paper we introduce and study the concept of a D-basic algebra, this being an algebra $(\mathrm{A}, \Delta, \neg, 1)$ of type $(2,1,0)$ with the property that the underlying poset $(\mathrm{A}, \leq)$, defined by $\mathrm{x} \geq \mathrm{y}$ if and only if $\neg \mathrm{x} \Delta \mathrm{y}=\neg 1$, is a bounded lattice and, for each $a \in A$, the mapping $(x \rightarrow \neg x \Delta$ a) is an antitone involution on the principal ideal (a] $=\{\mathrm{x} \in \mathrm{A} \mid \mathrm{a} \geq$ $\mathrm{x}\}$. The name 'D-basic algebra' is used because these algebras capture common features of many known structures such as Boolean algebras, orthomodular lattices, lattice Deffect algebras. we have special attention to lattice D-effect algebras, which were originally defined as partial algebras $(\mathrm{E}, \Delta, 0,1)$, but where the presence of the meet operation allowe one to replace partial $\Delta$ by D-total $\Delta$. The intent of the present paper is to establish similar results for D-effect algebras in the context of commutative directoids; we prove that every $D$-effect algebra $(\mathrm{E}, \Delta, 0,1)$ can be made into a $\mathrm{D}$ total algebra $(\mathrm{E}, \Delta, \neg, 1)$.

We first recall several relevant notions.

Definition 1.1 [8]: A commutative directoids is a commutative, idempo-tent groupoid (A,.) satisfying the equation $\mathrm{x} .((\mathrm{x} . \mathrm{y}) . \mathrm{z})=(\mathrm{x} \cdot \mathrm{y}) . \mathrm{z}$.

Remark 1.2 For instance, every semilattice is a commutative directoid. It can easily be seen that the stipulation

$$
\mathrm{x} \geq \mathrm{y} \text { if and only if } \mathrm{x} \cdot \mathrm{y}=\mathrm{y}
$$

defines a partial order on A such that, for every $x, y \in A, x . y$ is a lower bound of $\{x, y\}$. Thus the poset $(A, \leq)$ is downwards directed. Conversely, we may associate a commutative directoid to an arbitrary downwards directed set by letting $\mathrm{x} . \mathrm{y}=\mathrm{y} . \mathrm{x}$ be some lower bound of $\{\mathrm{x}, \mathrm{y}\}$, such that whenever $\mathrm{x}, \mathrm{y}$ are comparable, $\mathrm{x} . \mathrm{y}=\mathrm{y}$. $\mathrm{x}$ is the least of $\mathrm{x}, \mathrm{y}$.

Like in semilattices, we could define the dual order by $\mathrm{x} \geq$ $\mathrm{y}$ if and only if $\mathrm{x} . \mathrm{y}=\mathrm{x}$, in which case $\mathrm{x} . \mathrm{y}$ is an upper bound of $\{x, y\}$. But we shall be concerned with the partial order given by (1). Accordingly, we shall write $\Pi$ instead of. in order to emphasize that $\mathrm{x} \sqcap \mathrm{y}$ is less than or equal to $\mathrm{x}, \mathrm{y}$.

Definition 1.3 [3] An antitone involution on a poset $(\mathrm{P}, \leq)$ is a mapping $\beta: \mathrm{P} \rightarrow \mathrm{P}$ such that, for all $\mathrm{x}, \mathrm{y} \in \mathrm{P}$,

$$
\begin{gathered}
x \geq y \Rightarrow \beta(y) \geq \beta(x), \\
\beta(\beta(x))=x .
\end{gathered}
$$

By a commutative directoid with sectional antitone involutions we shall mean a system $\left(\mathrm{A}, \Pi,\left(\beta_{\mathrm{a}}\right)_{\mathrm{a} \in \mathrm{A}}, 0,1\right)$ where

$(\mathrm{A}, \Pi)$ is a commutative directoid with a least element 0 and a greatest element 1 , and every section (a] is equipped with an antitone involution $\beta_{\mathrm{a}}$.

In particular, if $(A, \Pi)$ is a semilattice, then the underlying poset is a lattice in which $\beta_{1}\left(\beta_{1}(\mathrm{x}) \sqcap \beta_{1}(\mathrm{y})\right)$ is the supremum of $\{\mathrm{x}, \mathrm{y}\}$, and hence we may say that $\left(\mathrm{A}, \Pi,\left(\beta_{\mathrm{a}}\right)_{\mathrm{a} \in \mathrm{A}}, 0,1\right)$ is a 
lattice with sectional antitone involutions.

\section{Weak D-Basic Algebra}

Definition 2.1 A Weak D-basic algebra is an algebra (A, $\Delta, \neg, 1)$ of type $(2,1,0)$ satisfying the following identities and quasi-identity (where 1 is an abbreviation for $\neg 0$ ):

(DW1) $\mathrm{x} \Delta 1=\mathrm{x}$,

(DW2) $\neg \neg \mathrm{x}=\mathrm{x}$,

(DW3) $\neg(\neg \mathrm{x} \Delta \mathrm{y}) \Delta \mathrm{y}=\neg(\neg \mathrm{y} \Delta \mathrm{x}) \Delta \mathrm{x}$,

(DW4) x $\Delta(\neg(\neg(\neg(\mathrm{x} \Delta \mathrm{y}) \Delta \mathrm{y}) \Delta \mathrm{z}) \Delta \mathrm{z})=0$,

(DW5) $\neg \mathrm{x} \Delta(\mathrm{y} \Delta \mathrm{x})=0$,

(DW6) $\neg \mathrm{x} \Delta \mathrm{y}=0 \& \neg \mathrm{y} \Delta \mathrm{z}=0 \Rightarrow \neg(\neg \mathrm{z} \Delta \mathrm{x}) \Delta(\neg \mathrm{y}$ $\Delta \mathrm{x})=0$.

These algebras contains the equations $\mathrm{x} \Delta 0=0=0 \Delta \mathrm{x}$. Specifically, if $(\mathrm{A}, \Delta, \neg, 0)$ is a weak D-basic algebra and if we put

$$
\mathrm{x} \sqcap \mathrm{y}=\neg(\neg \mathrm{x} \Delta \mathrm{y}) \Delta \mathrm{y},
$$

then $(A, \Pi)$ is a commutative directoid with a least element 0 and a greatest element 1 , such that the underlying order $\leq$ is given by:

$$
\mathrm{x} \geq \mathrm{y} \text { if and only if } \mathrm{x} \sqcap \mathrm{y}=\mathrm{y} \text { if and only if } \neg \mathrm{x} \Delta \mathrm{y}=0
$$

For each $\mathrm{a} \in \mathrm{A},(\mathrm{x} \rightarrow \neg \mathrm{x} \Delta \mathrm{a})$ is an antitone involution on $(\mathrm{a}]=\{\mathrm{x} \in \mathrm{A} \mid \mathrm{a} \geq \mathrm{x}\}$. Conversely, if $\left(\mathrm{A}, \Pi,\left(\beta_{\mathrm{a}}\right)_{\mathrm{a} \in \mathrm{A}}, 0,1\right)$ is a commutative directoid with sectional antitone involutions, then we can define $\Delta$ and $\neg$ as $\mathrm{x} \Delta \mathrm{y}=\beta_{\mathrm{y}}\left(\beta_{1}(\mathrm{x}) \sqcap \mathrm{y}\right)$ and $\neg \mathrm{x}$ $=\beta_{1}(\mathrm{x})$, respectively, and $(\mathrm{A}, \Delta, \neg, 0)$ becomes a weak $D$ basic algebra in which $\mathrm{x} \Delta \mathrm{y}=\neg(\neg \mathrm{x} \Delta \mathrm{y}) \Delta \mathrm{y}$ and $\beta_{\mathrm{a}}(\mathrm{x})=$ $\neg \mathrm{x} \Delta$ a. In every Weak D-basic algebra, in addition to the 'meat-like' operation $\Pi$, we can introduce the dual 'join-like' operation $\sqcup$ by

$$
\mathrm{x} \sqcup \mathrm{y}=\neg(\neg \mathrm{x} \sqcap \neg \mathrm{y}) .
$$

Then we have $x \geq y$ if and only if $x \sqcup y=x$, and the structure $(A, \sqcup, \Pi)$ is a $\lambda$-lattice in the sense of [9], i.e., both $(\mathrm{A}, \Pi)$ and $(\mathrm{A}, \sqcup)$ are commutative directoids and the absorption laws

$\mathrm{x} \sqcap(\mathrm{x} \sqcup \mathrm{y})=\mathrm{x}=\mathrm{x} \sqcup(\mathrm{x} \sqcap \mathrm{y})$ are satisfied.

Definition 2.2 A D-basic algebra is an algebra (A, $\Delta, \neg$, 0 ) of type $(2,1,0)$ satisfying the identities (again, $1=\neg 0$ )

(DB1) $\mathrm{x} \Delta 1=\mathrm{x}$,

(DB2) $\neg \neg \mathrm{x}=\mathrm{x}$,

(DB3) $\neg(\neg \mathrm{x} \Delta \mathrm{y}) \Delta \mathrm{y}=\neg(\neg \mathrm{y} \Delta \mathrm{x}) \Delta \mathrm{x}$,

(DB4) $\neg(\neg(\neg(\mathrm{x} \Delta \mathrm{y}) \Delta \mathrm{y}) \Delta \mathrm{z}) \Delta(\mathrm{x} \Delta \mathrm{z})=0$.

Originally, we required $\mathrm{x} \Delta 0=0=0 \Delta \mathrm{x}$.

Every D-basic algebra is a Weak D-basic algebra, and the above assignment between weak D-basic algebras and commutative directoids with sectional antitone involutions, restricted to D-basic algebras, furnishes a one-to-one correspondence between D-basic algebras and lattices with sectional antitone involutions. In other words, a weak $D$ basic algebra $(\mathrm{A}, \Delta, \neg, 0)$ is a D-basic algebra if and only if $\left(\mathrm{A}, \sqcap,\left(\beta_{\mathrm{a}}\right)_{\mathrm{a}} \in \mathrm{A}, 0,1\right)$ is a lattice with sectional antitone involutions.
The axioms (DW3) - (DW6) may be rewritten in terms of $\geq$ and $\Pi$ as follows:

(DW3') $\mathrm{x} \sqcap \mathrm{y}=\mathrm{y} \sqcap \mathrm{x}$

(DW4') $\mathrm{x} \geq(\mathrm{x} \sqcap \mathrm{y}) \sqcap \mathrm{z}$,

(DW5') $\mathrm{x} \geq \mathrm{y} \Delta \mathrm{x}$

(DW6') $\mathrm{x} \geq \mathrm{y} \& \mathrm{y} \geq \mathrm{z} \Rightarrow \neg \mathrm{z} \Delta \mathrm{x} \geq \neg \mathrm{y} \Delta \mathrm{x}$.

Moreover, in every weak D-basic algebra we have

$$
\begin{gathered}
\mathrm{x} \Delta 0=0=0 \Delta \mathrm{x}, \\
1 \Delta \mathrm{x}=\mathrm{x}, \\
\neg(\mathrm{x} \sqcap \mathrm{y}) \Delta \mathrm{y}=\neg \mathrm{x} \Delta \mathrm{y} .
\end{gathered}
$$

Indeed, $0 \Delta \mathrm{x}=\neg 1 \Delta(\mathrm{x} \Delta 1)=0$ by (DW1) and (DW5), so $\mathrm{x} \Delta 0=\mathrm{x} \Delta(0 \Delta \neg \mathrm{x})=0$ by (DW2) and (DW5). Further, $1 \Delta \mathrm{x}=\neg 0 \Delta \mathrm{x}=(\neg 1 \Delta \mathrm{x}) \Delta \mathrm{x}=(\neg \mathrm{x} \Delta 1) \Delta 1$ $=\neg \neg \mathrm{x}=\mathrm{x}$ and $\neg(\mathrm{x} \sqcap \mathrm{y}) \Delta \mathrm{y}=\neg(\neg(\neg \mathrm{x} \Delta \mathrm{y}) \Delta \mathrm{y}) \Delta \mathrm{y}=$ $(\neg \mathrm{x} \Delta \mathrm{y}) \sqcap \mathrm{y}=\neg \mathrm{x} \Delta \mathrm{y}$.

Proposition 2.3 A D-algebra $\mathrm{A}=(\mathrm{A}, \Delta, \neg, 0)$ satisfying (DW1)-(DW4) is a Weak D-basic algebra if and only if it satisfies the identity

$$
\neg(\neg((\mathrm{x} \sqcap \mathrm{y}) \sqcap \mathrm{z}) \Delta \mathrm{x}) \Delta(\neg \mathrm{y} \Delta \mathrm{x})=0 .
$$

Proof. Let A be a Weak D-basic algebra. We have $\mathrm{x} \geq \mathrm{x} \Pi$ $\mathrm{y}$ and $\mathrm{x} \sqcap \mathrm{y} \geq(\mathrm{x} \sqcap \mathrm{y}) \sqcap \mathrm{z}$, i.e., $\neg \mathrm{x} \Delta(\mathrm{x} \sqcap \mathrm{y})=0$ and $\neg(\mathrm{x} \sqcap$ y) $\Delta((\mathrm{x} \sqcap \mathrm{y}) \sqcap \mathrm{z})=0$, which yields

$$
\neg(\neg((\mathrm{x} \sqcap \mathrm{y}) \sqcap \mathrm{z}) \Delta \mathrm{x}) \Delta(\neg(\mathrm{x} \sqcap \mathrm{y}) \Delta \mathrm{x})=0
$$

by (DW6). But $\neg(\mathrm{x} \sqcap \mathrm{y}) \Delta \mathrm{x}=\neg(\mathrm{y} \sqcap \mathrm{x}) \Delta \mathrm{x}=\neg \mathrm{y} \Delta \mathrm{x}$ by (8), hence A fulfils (9). Conversely, assume that A satisfies (DW1)-(DW4) and (9). We first observe that x $\sqcap 1=\neg(\neg \mathrm{x}$ $\Delta 1) \Delta 1=\neg \neg \mathrm{x}=\mathrm{x}$, whence $0 \Delta \mathrm{x}=\neg 1 \Delta((1 \sqcap 1) \sqcap \mathrm{x})=$ 0 by (DW4') and (8). This yields $1 \Delta \mathrm{x}=\neg 0 \Delta \mathrm{x}=\neg \neg 1 \Delta$ $\mathrm{x}) \Delta \mathrm{x}=1 \sqcap \mathrm{x}=\mathrm{x}$ and so $\mathrm{x} \sqcap 0=\neg(\neg 0 \Delta \mathrm{x}) \Delta \mathrm{x}=\neg \mathrm{x} \Delta$ $\mathrm{x}=\neg \mathrm{x} \Delta((\mathrm{x} \sqcap 1) \sqcap 1)=0$. Further, $\neg \mathrm{x} \Delta \mathrm{y}=0$ entails $\mathrm{x} \sqcap$ $\mathrm{y}=\neg(\neg \mathrm{x} \Delta \mathrm{y}) \Delta \mathrm{y}=\neg 0 \Delta \mathrm{y}=1 \Delta \mathrm{y}=\mathrm{y}$.

Now, if we substitute 0 and $\neg \mathrm{y}$ for $\mathrm{z}$ and $\mathrm{y}$, respectively, by (9) we obtain $0=\neg(\neg((\mathrm{x} \sqcap \neg \mathrm{y}) \sqcap 0) \Delta \mathrm{x}) \Delta(\neg \neg \mathrm{y} \Delta \mathrm{x})=$ $\neg(\neg 0 \Delta \mathrm{x}) \Delta(\mathrm{y} \Delta \mathrm{x})=\neg \mathrm{x} \Delta(\mathrm{y} \Delta \mathrm{x})$,

which is (DW5). Finally, if $\neg \mathrm{x} \Delta \mathrm{y}=0$ and $\neg \mathrm{y} \Delta \mathrm{z}=0$, then (x $\sqcap \mathrm{y}) \sqcap \mathrm{z}=\mathrm{z}$ and by (9) we have

$$
\begin{aligned}
0=\neg & (\neg((\mathrm{x} \sqcap \mathrm{y}) \sqcap \mathrm{z}) \Delta \mathrm{x}) \Delta(\neg \mathrm{y} \Delta \mathrm{x}) \\
& =\neg(\neg \mathrm{z} \Delta \mathrm{x}) \Delta(\neg \mathrm{y} \Delta \mathrm{x}),
\end{aligned}
$$

which settles (DW6). Thus A is a Weak D-basic algebra.

Another central concept is that of a D-effect algebra. We have a $D$-effect algebra is a system $(\mathrm{E}, \Delta, 0,1)$ where 0,1 are distinguished elements of $\mathrm{E}$ and $\Delta$ is a partial binary operation on E such that

(DEA1) $\mathrm{x} \Delta \mathrm{y}=\mathrm{y} \Delta \mathrm{x}$ if one side is defined,

(DEA2) ( $\mathrm{x} \Delta \mathrm{y}) \Delta \mathrm{z}=\mathrm{x} \Delta(\mathrm{y} \Delta \mathrm{z})$ if one side is defined,

(DEA3) for every $\mathrm{x} \in \mathrm{E}$ there exists a unique $\mathrm{x}^{\prime} \in \mathrm{E}$ with $\mathrm{x}^{\prime}$ $\Delta \mathrm{x}=0$,

(DEA4) if $\mathrm{x} \Delta 0$ is defined then $\mathrm{x}=1$.

Every $D$-effect algebra bears a natural partial order given by $\mathrm{x} \geq \mathrm{y}$ if and only if $\mathrm{y}=\mathrm{x} \Delta \mathrm{z}$ for some $\mathrm{z} \in \mathrm{E}$. 
The poset $(\mathrm{E}, \leq)$ is bounded, 0 is the bottom element and 1 is the top element. If, moreover, $(\mathrm{E}, \leq)$ is a lattice, then $(\mathrm{E}, \Delta$, $0,1)$ is called a lattice D-effect algebra. In every D-effect algebra, a partial binary operation $\nabla$ can be defined as follows:

$\mathrm{x} \nabla \mathrm{y}$ exists and equals $\mathrm{z}$ if and only if $\mathrm{z}=\left(\mathrm{x}^{\prime} \Delta \mathrm{y}\right)^{\prime}$.

(Thus $\mathrm{x} \nabla \mathrm{y}$ is defined if and only if $\mathrm{y} \geq \mathrm{x}$.) The system (E, $\leq, \nabla, 0,1)$ so obtained is called a D-poset.

When doing calculations, the following properties of $D$ effect algebras and D-posets will be useful:

Remark 2.4

(1) $\mathrm{x} \Delta 1=\mathrm{x}, \mathrm{x} \nabla 1=\mathrm{x}, \mathrm{x} \nabla \mathrm{x}=1,0 \nabla \mathrm{x}=\mathrm{x}^{\prime}$;

(2) $x \geq y$ if and only if $y^{\prime} \geq x^{\prime}$;

(3) $x \Delta y$ is defined if and only if $x \geq y^{\prime}$ if and only if $y \geq$ $\mathrm{x}^{\prime}$; in this case, $\mathrm{x} \Delta \mathrm{y}=\left(\mathrm{x}^{\prime} \nabla \mathrm{y}\right)^{\prime}=\left(\mathrm{y}^{\prime} \nabla \mathrm{x}\right)^{\prime}$;

(4) If $\mathrm{x} \Delta \mathrm{y}$ is defined, then so is $\mathrm{x}_{1} \Delta \mathrm{y}_{1}$ for all $\mathrm{x}_{1} \geq \mathrm{x}$ and $\mathrm{y}_{1} \geq \mathrm{y}$

(5) $\mathrm{x} \Delta \mathrm{y}=\mathrm{z}$ if and only if $\mathrm{x}^{\prime}=\mathrm{y} \Delta \mathrm{z}^{\prime}$ if and only if $\mathrm{y}^{\prime}=\mathrm{x}$ $\Delta z^{\prime}$

(6) If $\mathrm{x} \geq \mathrm{y}$, then $\mathrm{x} \nabla \mathrm{y}=\left(\mathrm{x}^{\prime} \Delta \mathrm{y}\right)^{\prime} \geq \mathrm{x}$ and $\mathrm{x} \nabla$ ( $\left.\mathrm{x} \nabla \mathrm{y}\right)=\mathrm{y}$;

(7) $\mathrm{x} \geq \mathrm{y} \geq \mathrm{z}$ implies $\mathrm{z} \nabla \mathrm{y} \geq \mathrm{z} \nabla \mathrm{x}$ and ( $\nabla \nabla \mathrm{x}) \nabla(\mathrm{z} \nabla \mathrm{y})$ $=\mathrm{y} \nabla \mathrm{x}$; in particular $\mathrm{x}^{\prime} \nabla \mathrm{y}^{\prime}=\mathrm{y} \nabla \mathrm{x}$;

(8) $\mathrm{x} \geq \mathrm{y} \geq \mathrm{z}$ implies $\mathrm{y} \nabla \mathrm{x} \geq \mathrm{z} \nabla \mathrm{x}$ and $(\mathrm{z} \nabla \mathrm{x}) \nabla(\mathrm{y} \nabla \mathrm{x})=$ $\mathrm{z} \nabla \mathrm{y}$.

\section{The Relation Between D-Effect Algebras and Weak D-Basic Algebras}

Theorem 3.1 Let $\mathrm{A}=(\mathrm{A}, \Delta, \neg, 0)$ be a Weak D-basic algebra. Define the partial binary relation $\Delta$ on $\mathrm{A}$ as follows: $\mathrm{x} \Delta \mathrm{y}$ is defined if and only if $\mathrm{x} \geq \neg \mathrm{y}$, and in this case $\mathrm{x} \Delta \mathrm{y}=$ $\mathrm{x} \Delta \mathrm{y}$. Then $\varepsilon(\mathrm{A})=(\mathrm{A}, \Delta, 0,1)$ is a $\mathrm{D}$-effect algebra if and only if A satisfies the quasi-identity

$\mathrm{x} \geq \neg \mathrm{y} \& \mathrm{x} \Delta \mathrm{y} \geq \neg \mathrm{z} \Rightarrow(\mathrm{x} \Delta \mathrm{y}) \Delta \mathrm{z}=\mathrm{x} \Delta(\mathrm{z} \Delta \mathrm{y})$.

Moreover, over Weak D-basic algebras, (10) is equivalent to the identity

$$
\begin{gathered}
(\mathrm{x} \Delta \mathrm{y}) \Delta(\neg(\mathrm{x} \Delta \mathrm{y}) \sqcup \mathrm{z})=(\mathrm{x} \sqcup \neg \mathrm{y}) \Delta((\neg(\mathrm{x} \Delta \mathrm{y}) \sqcup \mathrm{z}) \\
\Delta \mathrm{y}) .
\end{gathered}
$$

Proof. Suppose that $\varepsilon(\mathrm{A})$ is a D-effect algebra. If $\mathrm{x} \geq \neg \mathrm{y}$ and $\mathrm{x} \Delta \mathrm{y} \geq \neg \mathrm{z}$, then $\mathrm{x} \Delta \mathrm{y}$ and $(\mathrm{x} \Delta \mathrm{y}) \Delta \mathrm{z}$ exist, hence $\mathrm{y} \Delta \mathrm{z}$ and $\mathrm{x} \Delta(\mathrm{y} \Delta \mathrm{z})$ also exist and $(\mathrm{x} \Delta \mathrm{y}) \Delta \mathrm{z}=(\mathrm{x} \Delta \mathrm{y}) \Delta \mathrm{z}=\mathrm{x}$ $\Delta(\mathrm{y} \Delta \mathrm{z})=\mathrm{x} \Delta(\mathrm{z} \Delta \mathrm{y})=\mathrm{x} \Delta(\mathrm{z} \Delta \mathrm{y})$.

Conversely, let A satisfy (10). We shall verify that $E(A)$ is a D-algebra:

(EA1) Assume that $a \mathrm{~b}$ is defined. Since $\mathrm{a} \geq \neg \mathrm{b}$ if and only if $\mathrm{b} \geq \neg \mathrm{a}$, it follows that $\mathrm{b} \Delta \mathrm{a}$ is defined, too. By (10) we have $(1 \geq \neg \mathrm{a} \& 1 \Delta \mathrm{a} \geq \neg \mathrm{b}) \Rightarrow \mathrm{a} \Delta \mathrm{b}=\mathrm{b} \Delta$ a, so that a $\geq \neg \mathrm{b}$ entails a $\Delta \mathrm{b}=\mathrm{b} \Delta \mathrm{a}$.

(EA2) Let ( $\Delta \Delta$ b) $\Delta \mathrm{c}$ be defined, i.e., $\mathrm{a} \geq \neg \mathrm{b}$ and $\mathrm{a} \Delta \mathrm{b}=\mathrm{a}$ $\Delta \mathrm{b} \geq \neg \mathrm{c}$. Since $\mathrm{b} \geq \mathrm{a} \Delta \mathrm{b} \geq \neg \mathrm{c}$, also $\mathrm{b} \Delta \mathrm{c}=\mathrm{c} \Delta \mathrm{b}$ exists. Further, by (W6), $\mathrm{b} \geq \mathrm{a} \Delta \mathrm{b} \geq \neg \mathrm{c}$ implies c $\Delta \mathrm{b}=\neg \neg \mathrm{c} \Delta \mathrm{b}$ $\geq \neg(\mathrm{a} \Delta \mathrm{b}) \Delta \mathrm{b}=\neg \mathrm{a} \sqcap \mathrm{b}=\neg \mathrm{a}$, so a $\Delta(\mathrm{c} \Delta \mathrm{b})=\mathrm{a} \Delta(\mathrm{b} \Delta \mathrm{c})$ is defined. Analogously, if a $\Delta$ (b $\Delta$ c) exists, then so does (a $\Delta \mathrm{b}) \Delta \mathrm{c}$. By (10) we have $(\mathrm{a} \Delta \mathrm{b}) \Delta \mathrm{c}=(\mathrm{a} \Delta \mathrm{b}) \Delta \mathrm{c}=\mathrm{a} \Delta$ $(\mathrm{c} \Delta \mathrm{b})=\mathrm{a} \Delta(\mathrm{c} \Delta \mathrm{b})=\mathrm{a} \Delta(\mathrm{b} \Delta \mathrm{c})$.

(EA3) Clearly, we have $\neg \mathrm{a} \Delta \mathrm{a}=0$. If $\mathrm{b} \Delta \mathrm{a}=0$, then $\mathrm{b} \geq \neg$ $\mathrm{a}$ since $\mathrm{b} \Delta \mathrm{a}$ is defined, and $\neg \mathrm{b} \geq \mathrm{a}$ (i.e., $\mathrm{b} \leq \neg \mathrm{a}$ ) since $\mathrm{b} \Delta \mathrm{a}$ $=0$. Thus $\mathrm{b}=\neg \mathrm{a}$.

(EA4) Finally, if a $\Delta 0$ is defined, then $\mathrm{a} \geq \neg 0=1$, so $\mathrm{a}=1$.

It remains to show that (10) and (11) are equivalent over weak D-basic algebras.

In any weak D-basic algebra, $\mathrm{x} \sqcup \neg \mathrm{y} \geq \neg \mathrm{y}$ and, using (8),

$(\mathrm{x} \sqcup \neg \mathrm{y}) \Delta \mathrm{y}=\neg(\neg \mathrm{x} \sqcap \mathrm{y}) \Delta \mathrm{y}=\mathrm{x} \Delta \mathrm{y} \geq(\mathrm{x} \Delta \mathrm{y}) \sqcap \neg \mathrm{z}=$ $\neg(\neg(\mathrm{x} \Delta \mathrm{y}) \sqcup \mathrm{z})$.

Therefore, if (10) holds, then we have

$(\mathrm{x} \Delta \mathrm{y}) \Delta(\neg(\mathrm{x} \Delta \mathrm{y}) \sqcup \mathrm{z})=((\mathrm{x} \sqcup \neg \mathrm{y}) \Delta \mathrm{y}) \Delta(\neg(\mathrm{x} \Delta \mathrm{y}) \sqcup$ $\mathrm{z})=(\mathrm{x} \sqcup \neg \mathrm{y}) \Delta((\neg(\mathrm{x} \Delta \mathrm{y}) \sqcup \mathrm{z}) \Delta \mathrm{y})$,

which is (11). On the other hand, (11) evidently implies (10).

Corollary 3.2 Let $\mathrm{A}=(\mathrm{A}, \Delta, \neg, 0)$ be a D-basic algebra and let $\varepsilon(\mathrm{A})=(\mathrm{A}, \Delta, 0,1)$ be as in Theorem 3.1. Then $\varepsilon(\mathrm{A})$ is a lattice D-effect algebra if and only if A satisfies the quasiidentity (10).

However, as the following example shows, this is not true for Weak D-basic algebras since many different Weak Dbasic algebras can determine the same D-effect algebra.

Example 3.3 Let $(\mathrm{A}, \leq)$ be the poset

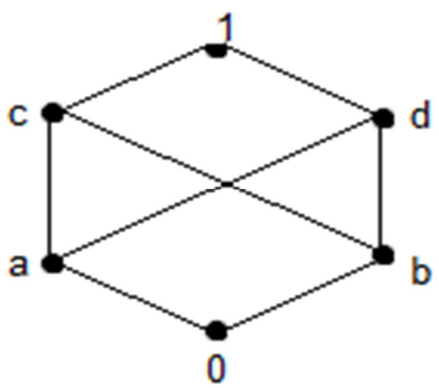

Figure 1. Weak D-basic algebra.

and let the sections (1] = A, (c] and (d] be equipped with the following antitone involutions:

$$
\begin{aligned}
& \beta_{1}: 1 \rightarrow 0,0 \rightarrow 1, d \rightarrow a, a \rightarrow d, b \rightarrow c, c \rightarrow b \\
& \beta_{c}: c \rightarrow 0,0 \rightarrow c, b \rightarrow a, a \rightarrow b \\
& \beta_{d}: d \rightarrow 0,0 \rightarrow d, b \rightarrow b, a \rightarrow a,
\end{aligned}
$$

the other sections admit unique antitone involutions. There are three possible ways in which we can associate a commutative directoid to $(\mathrm{A}, \geq)$, and consequently, there are three weak $D$ basic algebras with the underlying poset $(\mathrm{A}, \leq)$ :

In (table 1.) for $\mathrm{c} \Pi_{1} \mathrm{~d}=\mathrm{a}$ we get $\mathrm{A}_{1}=\left(\mathrm{A}, \Delta_{1}, \neg, 1\right)$ where

Table 1. Show the first way to weak D-basic algebra when $c \Pi_{l} d=a$.

\begin{tabular}{llllllll}
\hline$\Delta_{\mathbf{1}}$ & $\mathbf{0}$ & $\mathbf{a}$ & $\mathbf{b}$ & $\mathbf{c}$ & $\mathbf{d}$ & $\mathbf{1}$ & ᄀ \\
\hline 0 & 0 & 0 & 0 & 0 & 0 & 0 & 1 \\
$\mathrm{a}$ & 0 & 0 & 0 & $\mathrm{a}$ & 0 & $\mathrm{a}$ & $\mathrm{d}$ \\
$\mathrm{b}$ & 0 & 0 & 0 & 0 & $\mathrm{~b}$ & $\mathrm{~b}$ & $\mathrm{c}$ \\
$\mathrm{c}$ & 0 & $\mathrm{a}$ & 0 & $\mathrm{a}$ & $\mathrm{b}$ & $\mathrm{c}$ & $\mathrm{b}$ \\
$\mathrm{d}$ & 0 & 0 & $\mathrm{~b}$ & $\mathrm{~b}$ & $\mathrm{a}$ & $\mathrm{d}$ & $\mathrm{a}$ \\
1 & 0 & $\mathrm{~b}$ & $\mathrm{~b}$ & $\mathrm{c}$ & $\mathrm{d}$ & 1 & 0 \\
\hline
\end{tabular}

In (table 2.) for $\mathrm{c} \Pi_{2} \mathrm{~d}=\mathrm{b}$ we get $\mathrm{A}_{2}=\left(\mathrm{A}, \Delta_{2}, \neg, 1\right)$ where 
Table 2. Show the second way to weak D-basic algebra when $c \Pi_{2} d=b$.

\begin{tabular}{llllllll}
\hline$\Delta_{2}$ & 0 & A & B & c & d & 1 & $\neg$ \\
\hline 0 & 0 & 0 & 0 & 0 & 0 & 0 & 1 \\
$\mathrm{a}$ & 0 & 0 & 0 & $\mathrm{~b}$ & 0 & $\mathrm{a}$ & $\mathrm{d}$ \\
$\mathrm{b}$ & 0 & 0 & 0 & 0 & $\mathrm{a}$ & $\mathrm{b}$ & $\mathrm{c}$ \\
$\mathrm{c}$ & 0 & $\mathrm{a}$ & 0 & $\mathrm{a}$ & $\mathrm{b}$ & $\mathrm{c}$ & $\mathrm{b}$ \\
$\mathrm{d}$ & 0 & 0 & $\mathrm{~B}$ & $\mathrm{~b}$ & $\mathrm{a}$ & $\mathrm{d}$ & $\mathrm{a}$ \\
1 & 0 & $\mathrm{a}$ & $\mathrm{B}$ & $\mathrm{c}$ & $\mathrm{d}$ & 1 & 0 \\
\hline
\end{tabular}

In (table 3.) for $\mathrm{c} \Pi_{3} \mathrm{~d}=0$ we get $\mathrm{A}_{3}=\left(\mathrm{A}, \Delta_{3}, \neg, 1\right)$ where

Table 3. Show the third way to weak D-basic algebra when $c \Pi_{3} d=0$.

\begin{tabular}{llllllll}
\hline$\Delta_{3}$ & $\mathbf{0}$ & $\mathbf{a}$ & $\mathbf{B}$ & $\mathbf{c}$ & $\mathbf{d}$ & $\mathbf{1}$ & $\neg$ \\
\hline 0 & 0 & 0 & 0 & 0 & 0 & 0 & 1 \\
$\mathrm{a}$ & 0 & 0 & 0 & $\mathrm{C}$ & 0 & $\mathrm{a}$ & $\mathrm{d}$ \\
$\mathrm{b}$ & 0 & 0 & 0 & 0 & $\mathrm{~d}$ & $\mathrm{~b}$ & $\mathrm{c}$ \\
$\mathrm{c}$ & 0 & $\mathrm{a}$ & 0 & $\mathrm{a}$ & $\mathrm{b}$ & $\mathrm{c}$ & $\mathrm{b}$ \\
$\mathrm{d}$ & 0 & 0 & $\mathrm{~b}$ & $\mathrm{~b}$ & $\mathrm{a}$ & $\mathrm{d}$ & $\mathrm{a}$ \\
1 & 0 & $\mathrm{a}$ & $\mathrm{b}$ & $\mathrm{c}$ & $\mathrm{d}$ & 1 & 0 \\
\hline
\end{tabular}

All these Weak D-basic algebras induce the same D-effect algebra $\mathcal{E}\left(\mathrm{A}_{1}\right)=\mathcal{E}\left(\mathrm{A}_{2}\right)=\mathcal{E}\left(\mathrm{A}_{3}\right)=(\mathrm{A}, \Delta, 0,1)$ that clear in (table 4.) where

Table 4. Show that the three ways in Weak D-basic algebras induce the same D-effect algebra.

\begin{tabular}{llllllll}
\hline$\Delta$ & 0 & A & b & c & d & 1 & ᄀ \\
\hline 0 & $\cdot$ & $\cdot$ & $\cdot$ & $\cdot$ & $\cdot$ & 0 & 1 \\
$\mathrm{a}$ & $\cdot$ & $\cdot$ & $\cdot$ & $\cdot$ & 0 & $\mathrm{a}$ & $\mathrm{d}$ \\
$\mathrm{b}$ & $\cdot$ & $\cdot$ & $\cdot$ & 0 & $\cdot$ & $\mathrm{b}$ & $\mathrm{c}$ \\
$\mathrm{c}$ & $\cdot$ & $\cdot$ & 0 & $\mathrm{a}$ & $\mathrm{b}$ & $\mathrm{c}$ & $\mathrm{b}$ \\
$\mathrm{d}$ &. & 0 &. & $\mathrm{~b}$ & $\mathrm{a}$ & $\mathrm{d}$ & $\mathrm{a}$ \\
$\mathrm{l}$ & 0 & $\mathrm{a}$ & $\mathrm{b}$ & $\mathrm{c}$ & $\mathrm{d}$ & 1 & 0 \\
\hline
\end{tabular}

Where for any $\mathrm{x}, \mathrm{y} \in \mathrm{A}$ we have $\mathrm{x} \Delta \mathrm{y}=$. means $\mathrm{x} \Delta \mathrm{y}$ does not exist. Let $\mathrm{E}=(\mathrm{E}, \Delta, 0,1)$ be a D-effect algebra. Since the underlying poset $(\mathrm{E}, \leq)$ is bounded, it can be organized into a commutative directoid $(\mathrm{E}, \Pi)$. We shall simply say that the pair $(\mathrm{E}, \Pi)$ is a D-effect algebra with an associated commutative directoid.

Theorem 3.4 Let $(\mathrm{E}, \Pi)$ be a $D$-effect algebra $\mathrm{E}=(\mathrm{E}, \Delta, 0$, 1) with an associated commutative directoid. Define

$\mathrm{x} \Delta \mathrm{y}=\left(\mathrm{x}^{\prime} \sqcap \mathrm{y}\right)^{\prime} \Delta \mathrm{y}$ and $\neg \mathrm{x}=\mathrm{x}^{\prime}$.

Then DB $(\mathrm{E}, \Pi)=(\mathrm{E}, \Delta, \neg, 1)$ is a Weak D-basic algebra satisfying (10). Moreover, $\mathcal{E}(\mathrm{DB}$ (E, $\Pi)$ ), the D-effect algebra assigned to DB $(\mathrm{E}, \Pi)$ by Theorem 3.1, is just $\mathrm{E}$.

Proof. First, we prove that for each $\mathrm{a} \in \mathrm{E}, \beta_{\mathrm{a}}: \mathrm{x} \rightarrow \mathrm{x}^{\prime} \Delta \mathrm{a}$ is an anititone involution on (a]. For all $\mathrm{x} \in$ (a], we have $\mathrm{x}^{\prime} \Delta \mathrm{a}$ is defined since $x^{\prime} \geq a^{\prime}$, and $x^{\prime} \Delta a \leq a$. Thus $\beta_{a}$ is well defined. We also have $\beta_{\mathrm{a}}\left(\beta_{\mathrm{a}}(\mathrm{x})\right)=\left(\mathrm{x}^{\prime} \Delta \mathrm{a}\right)^{\prime} \Delta \mathrm{a}=\mathrm{x}$ because, by $(\mathrm{v}),\left(\mathrm{x}^{\prime}\right.$ $\Delta \mathrm{a})^{\prime} \Delta \mathrm{a}=\mathrm{x}$ if and only if $\left(\mathrm{x}^{\prime} \Delta \mathrm{a}\right)^{\prime \prime}=\mathrm{a} \Delta \mathrm{x}^{\prime}$. Finally, if $\mathrm{a} \geq \mathrm{x} \geq$ $\mathrm{y}$, then $\beta_{\mathrm{a}}(\mathrm{y})=\mathrm{y}^{\prime} \Delta \mathrm{a} \geq \mathrm{x}^{\prime} \Delta \mathrm{a}=\beta_{\mathrm{a}}(\mathrm{x})$, proving that $\beta_{\mathrm{a}}$ is an anititone involution.

We know that if we put $\mathrm{x} \Delta_{1} \mathrm{y}=\beta_{\mathrm{y}}\left(\beta_{1}(\mathrm{x}) \sqcap \mathrm{y}\right)$ and $\neg \mathrm{x}=$ $\mathrm{x}^{\prime}$, then $\left(\mathrm{E}, \Delta_{1}, \neg, 1\right)$ becomes a Weak D-basic algebra. But $\mathrm{x} \Delta_{1} \mathrm{y}=\beta_{\mathrm{y}}\left(\beta_{1}(\mathrm{x}) \sqcap \mathrm{y}\right)=\left(\left(\mathrm{x}^{\prime} \Delta 1\right) \sqcap \mathrm{y}\right)^{\prime} \Delta \mathrm{y}=\left(\mathrm{x}^{\prime} \sqcap \mathrm{y}\right)^{\prime} \Delta \mathrm{y}=\mathrm{x}$ $\Delta \mathrm{y}$. Therefore, DB $(\mathrm{E}, \Pi)$ is a Weak D-basic algebra.

Now, we prove that DB $(E, \Pi)$ satisfies the quasi-identity (10). It is obvious that whenever $\mathrm{x} \Delta \mathrm{y}$ is defined in $\mathrm{E}$ (i.e., $\mathrm{x}$ $\left.\geq \mathrm{y}^{\prime}=\neg \mathrm{y}\right)$.

Then $\mathrm{x} \Delta \mathrm{y}=\left(\mathrm{x}^{\prime} \sqcap \mathrm{y}\right)^{\prime} \Delta \mathrm{y}=\mathrm{x} \Delta \mathrm{y}$. Hence if $\mathrm{x} \geq \neg \mathrm{y}$ and $\mathrm{x}$ $\Delta \mathrm{y} \geq \neg \mathrm{z}$, then $(\mathrm{x} \Delta \mathrm{y}) \Delta \mathrm{z}=(\mathrm{x} \Delta \mathrm{y}) \Delta \mathrm{z}=\mathrm{x} \Delta(\mathrm{y} \Delta \mathrm{z})=\mathrm{x} \Delta$ $(\mathrm{z} \Delta \mathrm{y})=\mathrm{x} \Delta(\mathrm{z} \Delta \mathrm{y})$, which settles (10). The last assertion is clear.

Example 3.5 Let $\mathrm{E}$ be the D-effect algebra we have obtained in Example 3.3. If we put $\mathrm{c} \Pi_{1} \mathrm{~d}=\mathrm{a}$ then DB (E, $\Pi_{1}$ ) is just the Weak D-basic algebra $\mathrm{A}_{1}$ from Example 3.3. Analogously, if $\mathrm{c} \Pi_{2} d=b$ then DB $\left(E, \Pi_{2}\right)=A_{2}$, and for $c \Pi_{3}$ $\mathrm{d}=0$ we have $\operatorname{DB}\left(\mathrm{E}, \Pi_{3}\right)=\mathrm{A}_{3}$.

There is a one-to-one correspondence between Weak D-basic algebras satisfying (10) (respectively, (11)) and pairs (E, П) where $\mathrm{E}=(\mathrm{E}, \Delta, 0,1)$ is a D-effect algebra with an associated commutative directoid $(\mathrm{E}, \Pi)$. Namely, the assignment

$$
\mathrm{A} \rightarrow(\mathcal{E}(\mathrm{A}), \Pi),
$$

where $\mathcal{E}(\mathrm{A})$ is as in Theorem 3.1 and $\mathrm{x} \sqcap \mathrm{y}=\neg(\neg \mathrm{x} \Delta \mathrm{y}) \Delta$ $\mathrm{y}$, is a bijection the inverse of which is

$$
(\mathrm{E}, \Pi) \rightarrow \mathrm{DB}(\mathrm{E}, \sqcap),
$$

where DB $(\mathrm{E}, \Pi)$ is defined in Theorem 3.4.

Let $\mathrm{E}=(\mathrm{E}, \Delta, 0,1)$ be a D-effect algebra. When constructing $(E, \Pi)$, we so far have not taken care of existing infima we only required that $\mathrm{x} \sqcap \mathrm{y}=\mathrm{y} \Pi \mathrm{x}$ is $\min \{\mathrm{x}, \mathrm{y}\}$ provided $\mathrm{x}, \mathrm{y}$ are comparable. Of course, this means that DB (E, $\Pi$ ) need not be a D-basic algebra even though $\mathrm{E}$ is a lattice D-effect algebra. The situation can be improved if we define $\Pi$ in such a way that the following condition holds:

If $\inf \{x, y\}$ exists, then $x \sqcap y=y \sqcap x=\inf \{x, y\}$.

Corollary 3.6 Let $(\mathrm{E}, \Pi)$ be a D-effect algebra with an associated commutative directoid that satisfies the condition (12). Then DB (E, $\Pi$ ) is a weak D-basic algebra, and if $\mathrm{E}$ is $a$ lattice D-effect algebra, then DB (E, $\Pi)$ is a D-basic algebra.

Proof. By Theorem 3.4, DB (E, $\Pi$ ) is a Weak D-basic algebra. Further, we know that $\mathrm{DB}(\mathrm{E}, \Pi)$ is a D-basic algebra if and only if the corresponding commutative directoid with sectional antitone involutions $\left(\mathrm{E}, \Pi,\left(\beta_{\mathrm{a}}\right)_{\mathrm{a} \in \mathrm{A}}, 0\right.$, 1), where $\beta_{\mathrm{a}}(\mathrm{x})=\mathrm{x}^{\prime} \Delta$ a for $\mathrm{x} \leq \mathrm{a}$, is actually a lattice with sectional antitone involutions, which is the case when $(E, \Pi)$ is a semilattice. Hence, if $\mathrm{E}$ is a lattice D-effect algebra, then, owing to $(12),(\mathrm{E}, \Pi)$ is a semilattice, and it follows that DB $(\mathrm{E}, \Pi)$ is a D-basic algebra.

\section{Compatibility in D-Effect Algebra}

Difination 4.1 We shall say that two elements $\mathrm{x}$, y in a $D$ effect algebra $\mathrm{E}$ are said to be compatible (in symbols $\mathrm{x} \leftrightarrow \mathrm{y}$ ) if there exist $\mathrm{u}, \mathrm{v} \in \mathrm{E}$ such that $\mathrm{u} \geq \mathrm{x}, \mathrm{y} \geq \mathrm{v}$ and $\mathrm{x} \nabla \mathrm{u}=\mathrm{v} \nabla \mathrm{y}$. This is equivalent to the existence of $z \in E$ with $x, y \geq z, z \nabla$ $\mathrm{x} \geq \mathrm{y}$ and $\mathrm{z} \nabla \mathrm{y} \geq \mathrm{x}$. But $\mathrm{z} \nabla \mathrm{x} \geq \mathrm{y} \geq \mathrm{z}$ implies $\mathrm{z} \nabla \mathrm{y} \geq \mathrm{z} \nabla$ ( $\mathrm{z}$ $\nabla \mathrm{x})=\mathrm{x}$, and conversely, $\mathrm{z} \nabla \mathrm{y} \geq \mathrm{x} \geq \mathrm{z}$ entails $\mathrm{z} \nabla \mathrm{x} \geq \mathrm{z} \nabla$ (z $\nabla \mathrm{y})=\mathrm{y}$. Therefore,

$$
\mathrm{x} \leftrightarrow \mathrm{y} \text { if and only if there is } \mathrm{z} \text { such that } \mathrm{x}, \mathrm{y} \geq \mathrm{z} \text { and } \mathrm{z} \nabla \mathrm{x} \geq \mathrm{y} \text {. }
$$


In general we have:

Proposition 4.2 Let $(\mathrm{E}, \Pi)$ and DB $(\mathrm{E}, \Pi)$ be as in Theorem 3.4. For every $\mathrm{x}, \mathrm{y} \in \mathrm{E}$, if $\mathrm{x} \Delta \mathrm{y}=\mathrm{y} \Delta \mathrm{x}$, then $\mathrm{x} \leftrightarrow \mathrm{y}$.

Proof. Let $\mathrm{z}=\mathrm{x} \Delta \mathrm{y}=\mathrm{y} \Delta \mathrm{x}$, i.e., $\left(\mathrm{x}^{\prime} \sqcap \mathrm{y}\right)^{\prime} \Delta \mathrm{y}=\left(\mathrm{y}^{\prime} \Pi \mathrm{x}\right)^{\prime}$ $\Delta \mathrm{x}$. Then $\mathrm{x}, \mathrm{y} \geq \mathrm{z}$ and $\mathrm{z} \nabla \mathrm{x}=\left(\left(\mathrm{y}^{\prime} \sqcap \mathrm{x}\right)^{\prime} \Delta \mathrm{x}\right) \nabla \mathrm{x}=\left(\mathrm{y}^{\prime} \sqcap \mathrm{x}\right)^{\prime} \geq$ $\mathrm{y}$, so that $\mathrm{x} \leftrightarrow \mathrm{y}$.

The reverse implication fails to be true. Let $\mathrm{E}$ be the $D$ - effect algebra from Examples 3.3 and 3.5. It can easily be seen that every two elements are compatible, while $\Delta_{\mathrm{i}}$ in A2 and $\mathrm{A} 3$ is not commutative (for instance, $\mathrm{a} \leftrightarrow \mathrm{c}$, but a $\Delta_{\mathrm{i}} \mathrm{c} \neq$ c $\Delta_{\mathrm{i}}$ a for $\left.\mathrm{i}=2,3\right)$.

In order to overcome this disadvantage, we define the 'meet-like' operation $\Pi$ in a D-effect algebra $\mathrm{E}=(\mathrm{E}, \Delta, 0,1)$ in the following way:

If $\mathrm{x} \leftrightarrow \mathrm{y}$, then $\mathrm{x} \sqcap \mathrm{y}=\mathrm{y} \sqcap \mathrm{x}=\mathrm{z}$ where $\mathrm{z} \leq \mathrm{x}, \mathrm{y}$ and $\mathrm{z} \nabla \mathrm{x} \geq \mathrm{y}$. At the same time, $\mathrm{x}^{\prime} \sqcap \mathrm{y}^{\prime}=\mathrm{y}^{\prime} \sqcap \mathrm{x}=(\mathrm{x} \nabla(\mathrm{z} \nabla \mathrm{y}))^{\prime}$.

We must show that the condition is correct.

If $\mathrm{z} \leq \mathrm{x}, \mathrm{y}$ and $\mathrm{z} \nabla \mathrm{x} \geq \mathrm{y}$, then $\mathrm{x} \nabla(\mathrm{z} \nabla \mathrm{y})=\mathrm{y} \nabla(\mathrm{z} \nabla \mathrm{x})$. Indeed, if we put $\mathrm{w}=\mathrm{x} \nabla(\mathrm{z} \nabla \mathrm{y})$ then $\mathrm{w} \Delta(\mathrm{z} \nabla \mathrm{y})=\mathrm{x}$ and $\mathrm{w}$ $\Delta(\mathrm{z} \nabla \mathrm{y}) \Delta(\mathrm{z} \nabla \mathrm{x})=\mathrm{x} \Delta(\mathrm{z} \nabla \mathrm{x})=\mathrm{z}$, whence $\mathrm{w} \Delta(\mathrm{z} \nabla \mathrm{x})=\mathrm{z}$ $\nabla(\mathrm{z} \nabla \mathrm{y})=\mathrm{y}$. So $\mathrm{w}=\mathrm{y} \nabla(\mathrm{z} \nabla \mathrm{x})$ and $(\mathrm{x} \nabla(\mathrm{z} \nabla \mathrm{y}))^{\prime}=(\mathrm{y} \nabla(\mathrm{z}$ $\nabla \mathrm{x}))^{\prime}$

Obviously, $\mathrm{w}^{\prime} \leq \mathrm{x}^{\prime}, \mathrm{y}^{\prime}$.

We have $\mathrm{w}^{\prime} \nabla \mathrm{x}^{\prime}=\mathrm{x} \nabla \mathrm{w}=\mathrm{x} \nabla(\mathrm{x} \nabla(\mathrm{z} \nabla \mathrm{y}))=\mathrm{z} \nabla \mathrm{y}=\mathrm{y}^{\prime} \nabla \mathrm{z}^{\prime} \geq$ $\mathrm{y}^{\prime}$. by using remark $2.4(\mathrm{ii})$

Finally, $\left(\mathrm{x}^{\prime} \nabla\left(\mathrm{w}^{\prime} \nabla \mathrm{y}^{\prime}\right)\right)^{\prime}=\mathrm{z}$. Indeed, $\left(\mathrm{x}^{\prime} \nabla\left(\mathrm{w}^{\prime} \nabla \mathrm{y}^{\prime}\right)\right)^{\prime}=\mathrm{x} \Delta$ $\left(\mathrm{w}^{\prime} \nabla \mathrm{y}^{\prime}\right)=\mathrm{x} \Delta(\mathrm{y} \nabla \mathrm{w})$, thus $\left(\mathrm{x}^{\prime} \nabla\left(\mathrm{w}^{\prime} \nabla \mathrm{y}^{\prime}\right)\right)^{\prime}=\mathrm{z}$ if and only if $\mathrm{y} \nabla \mathrm{w}=\mathrm{z} \nabla \mathrm{x}$, which is true since $\mathrm{y} \nabla \mathrm{w}=\mathrm{y} \nabla(\mathrm{y} \nabla(\mathrm{z} \nabla$ $\mathrm{x}))=\mathrm{z} \nabla \mathrm{x}$.
Also observe that the condition (14) is 'compatible' with (12) in the sense that we may take $z=\inf \{x, y\}$ whenever inf $\{x, y\}$ exists. More precisely, if $x \sqcap y=\inf \{x, y\}$ and $x \leftrightarrow y$, then (x $\sqcap \mathrm{y}) \nabla \mathrm{x} \geq \mathrm{y}$, and if, in addition, also inf $\left\{\mathrm{x}^{\prime}, \mathrm{y}^{\prime}\right\}$ exists, then inf $\left\{x^{\prime}, y^{\prime}\right\}=x^{\prime} \sqcap y^{\prime}=(x \nabla((x \sqcap y) \nabla y))^{\prime}$.

Indeed, $\mathrm{x} \leftrightarrow \mathrm{y}$ yields the existence of $\mathrm{z}$ with $\mathrm{z} \leq \mathrm{x}, \mathrm{y}$ and $\mathrm{z}$ $\nabla \mathrm{x} \geq \mathrm{y}$. Since $\mathrm{x} \sqcap \mathrm{y}=\inf \{\mathrm{x}, \mathrm{y}\}$, we have $\mathrm{z} \leq \mathrm{x} \sqcap \mathrm{y} \leq \mathrm{x}$, whence $\mathrm{y} \leq \mathrm{z} \nabla \mathrm{x} \geq(\mathrm{x} \sqcap \mathrm{y}) \nabla \mathrm{x}$.

Further, assume that inf $\left\{x^{\prime}, y^{\prime}\right\}$ exists (equivalently, $\sup \{x$, $\mathrm{y}\}$ exists). We have to show that $\mathrm{x} \nabla((\mathrm{x} \sqcap \mathrm{y}) \nabla \mathrm{y})=\sup \{\mathrm{x}$, $\mathrm{y}\}$. Let $\mathrm{w}=\mathrm{x} \nabla((\mathrm{x} \sqcap \mathrm{y}) \nabla \mathrm{y})$. By what we have established above we know that $\mathrm{w}=\mathrm{y} \nabla((\mathrm{x} \sqcap \mathrm{y}) \nabla \mathrm{x})$ and $\mathrm{w} \geq \mathrm{x}, \mathrm{y}$. Thus $\mathrm{w} \geq \sup \{\mathrm{x}, \mathrm{y}\} \geq \mathrm{x}, \mathrm{y}$, whence

$$
\begin{aligned}
& \sup \{\mathrm{x}, \mathrm{y}\} \nabla \mathrm{w} \geq \mathrm{x} \nabla \mathrm{w}=\mathrm{x} \nabla(\mathrm{x} \nabla((\mathrm{x} \sqcap \mathrm{y}) \nabla \mathrm{y}))=(\mathrm{x} \sqcap \mathrm{y}) \nabla \mathrm{y}, \\
& \sup \{\mathrm{x}, \mathrm{y}\} \nabla \mathrm{w} \geq \mathrm{y} \nabla \mathrm{w}=\mathrm{y} \nabla(\mathrm{y} \nabla((\mathrm{x} \sqcap \mathrm{y}) \nabla \mathrm{x}))=(\mathrm{x} \sqcap \mathrm{y}) \nabla \mathrm{x} .
\end{aligned}
$$

It is known that $\sup \{(\mathrm{x} \sqcap \mathrm{y}) \nabla \mathrm{y},(\mathrm{x} \sqcap \mathrm{y}) \nabla \mathrm{x}\}=1$ if $\mathrm{x} \sqcap$ $\mathrm{y}$ is $\inf \{\mathrm{x}, \mathrm{y}\}$, and consequently, the above inequalities imply $\sup \{\mathrm{x}, \mathrm{y}\} \nabla \mathrm{w}=1$, so that $\sup \{\mathrm{x}, \mathrm{y}\}=\mathrm{w}$ as desired.

Summarizing, we have proved that in every $D$-effect algebra $\mathrm{E}=(\mathrm{E}, \Delta, 0,1)$, the operation $\Pi$ can always be defined in such a way that it obeys the requirements of the condition (14). The next result says, that $x, y$ are compatible in $\mathrm{E}$ if and only if $\mathrm{x}, \mathrm{y}$ commute in $\mathrm{DB}(\mathrm{E}, \Pi)$ $=(\mathrm{E}, \Delta, \neg, 0)$.

Theorem 4.3 Let $(\mathrm{E}, \Pi)$ be a D-effect algebra with an associated commutative directoid satisfying condition (14). Then DB (E, $\Pi)$ is a Weak D-basic algebra such that, for all $\mathrm{x}, \mathrm{y} \in \mathrm{E}$, the following are equivalent:

(i) $\mathrm{x} \leftrightarrow \mathrm{y}$,

(ii) $(\mathrm{x} \sqcap \mathrm{y}) \nabla \mathrm{y}=\mathrm{x} \nabla(\mathrm{x} \sqcup \mathrm{y})$,

(iii) $\mathrm{x} \Delta \mathrm{y}=\mathrm{y} \Delta \mathrm{x}$.

Proof. (i) $\Leftrightarrow$ (ii): Let $\mathrm{x} \leftrightarrow \mathrm{y}$. Then (x $\sqcap \mathrm{y}) \nabla \mathrm{y} \geq \mathrm{x}$ and $\mathrm{x} \sqcup$ $\mathrm{y}=\left(\mathrm{x}^{\prime} \sqcap \mathrm{y}^{\prime}\right)^{\prime}=\mathrm{x} \nabla((\mathrm{x} \sqcap \mathrm{y}) \nabla \mathrm{y})$, whence $\mathrm{x} \nabla(\mathrm{x} \sqcup \mathrm{y})=\mathrm{x}$ $\nabla(\mathrm{x} \nabla((\mathrm{x} \sqcap \mathrm{y}) \nabla \mathrm{y}))=(\mathrm{x} \sqcap \mathrm{y}) \nabla \mathrm{y}$. Conversely, if $(\mathrm{x} \sqcap \mathrm{y}) \nabla \mathrm{y}=$ $\mathrm{x} \nabla(\mathrm{x} \sqcup \mathrm{y})$, then certainly $\mathrm{x} \leftrightarrow \mathrm{y}$ because $\mathrm{x} \sqcap \mathrm{y} \leq \mathrm{x}, \mathrm{y}$ and $(\mathrm{x}$ $\sqcap$ y) $\nabla \mathrm{y} \geq \mathrm{x}$.

(i) $\Leftrightarrow$ (iii): By Proposition 4.2 we know that $\mathrm{x} \Delta \mathrm{y}=\mathrm{y} \Delta$ $\mathrm{x}$ implies $\mathrm{x} \leftrightarrow \mathrm{y}$. Hence, Then alsox' $\leftrightarrow \mathrm{y}$, which means ( $\mathrm{x}^{\prime} \sqcap$ y) $\nabla \mathrm{y}=\mathrm{x}^{\prime} \nabla\left(\mathrm{x}^{\prime} \sqcup \mathrm{y}\right)$ by (ii). We then have $(\mathrm{x} \Delta \mathrm{y})^{\prime}=\left(\left(\mathrm{x}^{\prime} \sqcap\right.\right.$ y)' $\Delta \mathrm{y})^{\prime}=\left(\mathrm{x}^{\prime} \sqcap \mathrm{y}\right) \nabla \mathrm{y}=\mathrm{x}^{\prime} \nabla\left(\mathrm{x}^{\prime} \sqcup \mathrm{y}\right)=\left(\mathrm{x}^{\prime} \sqcup \mathrm{y}\right)^{\prime} \nabla \mathrm{x}=\left(\mathrm{y}^{\prime} \sqcap \mathrm{x}\right)$ $\nabla \mathrm{x}=\left(\left(\mathrm{y}^{\prime} \sqcap \mathrm{x}\right)^{\prime} \Delta \mathrm{x}\right)^{\prime}=(\mathrm{y} \Delta \mathrm{x})^{\prime}$, thus $\mathrm{x} \Delta \mathrm{y}=\mathrm{y} \Delta \mathrm{x}$.

Definition 4.4 By a block of a Weak D-basic algebra (A, $\Delta, \neg, 0)$ we mean a subset $\mathrm{DB}$ of $\mathrm{A}$ which is maximal with respect to the property that $\mathrm{x} \Delta \mathrm{y}=\mathrm{y} \Delta \mathrm{x}$ for all $\mathrm{x}, \mathrm{y} \in \mathrm{DB}$. It is evident that every element of $\mathrm{A}$ is contained in a block.
Theorem 4.5 Let $(\mathrm{E}, \Pi)$ be a D-effect algebra with an associated commutative directoid satisfying the condition (14). Assume that for all $\mathrm{x}, \mathrm{y}, \mathrm{z} \in \mathrm{E}$, if $\mathrm{x} \leftrightarrow \mathrm{y}, \mathrm{x} \leftrightarrow \mathrm{z}$ and $\mathrm{y}$ $\Delta \mathrm{z}$ is defined, then $\mathrm{x} \leftrightarrow \mathrm{y} \Delta \mathrm{z}$. Then a block $\mathrm{DB}$ of $\mathrm{DB}(\mathrm{E}$, $\Pi)$ is a subalgebra of DB $(E, \Pi)$ if and only if $x \sqcap y \in D B$ for all $\mathrm{x}, \mathrm{y} \in \mathrm{DB}$.

Proof. Let DB be a block of DB (E, $\Pi)$. In view of Theorem 4.3, DB is a maximal set of pairwise compatible elements (i.e., DB is a maximal subset of $E$ such that $\mathrm{x} \leftrightarrow$ $\mathrm{y}$ for all $\mathrm{x}, \mathrm{y} \in \mathrm{DB})$. Since $\mathrm{x} \leftrightarrow 0$ and $\mathrm{x} \leftrightarrow 1$ for each $\mathrm{x} \in \mathrm{E}$ (this follows at once from (13)), it is plain that $0,1 \in \mathrm{DB}$. Also, $x \leftrightarrow y$ if and only if $x^{\prime} \leftrightarrow y$, hence $x \in D B$ if and only if $\neg \mathrm{x}=\mathrm{x}^{\prime} \in \mathrm{DB}$.

Suppose DB is closed under $\Pi$. If $x, y \in D B$, then also $\left(\mathrm{x}^{\prime} \sqcap \mathrm{y}\right)^{\prime} \in \mathrm{DB}$. Thus $\left(\mathrm{x}^{\prime} \sqcap \mathrm{y}\right)^{\prime} \leftrightarrow \mathrm{z}$ and $\mathrm{y} \leftrightarrow \mathrm{z}$ for every $\mathrm{z} \in$ $\mathrm{DB}$, whence $\mathrm{x} \Delta \mathrm{y}=\left(\mathrm{x}^{\prime} \sqcap \mathrm{y}\right)^{\prime} \Delta \mathrm{y} \in \mathrm{DB}$, proving that $\mathrm{DB}$ is a subalgebra of DB $(E, \Pi)$. Conversely, if $D B$ is a subalgebra of DB $(E, \Pi)$, then it is automatically closed with respect to $\sqcap$ because $\mathrm{x} \sqcap \mathrm{y}=\neg(\neg \mathrm{x} \Delta \mathrm{y}) \Delta \mathrm{y}$. The condition that $\mathrm{x} \leftrightarrow \mathrm{y}$ and $\mathrm{x} \leftrightarrow \mathrm{z}$ together yield $\mathrm{x} \leftrightarrow \mathrm{y} \Delta \mathrm{z}$ (if $\mathrm{y} \Delta \mathrm{z}$ exists) holds in lattice D-effect algebras, however, the next example shows that the operation $\Delta$ in Theorem 4.5 cannot be omitted.

Example 4.6 Let $\mathrm{E}$ be the set consisting of the following pairs of integers: $0=(0,0), \mathrm{a}=(1,2), \mathrm{b}=(1,1), \mathrm{c}=$ $(2,1), \mathrm{d}=(2,3), \mathrm{e}=(3,3), \mathrm{f}=(3,2), \mathrm{g}=(2,2)$ and $1=$ $(4,4)$. If we equip $E$ with $\Delta$ defined as the restriction to $\mathrm{E}$ of $\Delta$, then $\mathrm{E}=(\mathrm{E}, \Delta, 0)$ becomes a D-effect algebra. The underlying poset of $\mathrm{E}$ is as follows (notice that $(\mathrm{x}, \mathrm{y}) \geq$ $(u, v)$ if and only if $(x, y)=(u, v)$, or $x>u \& y>v)$ where 
$(\mathrm{x}, \mathrm{y}) \Delta(\mathrm{u}, \mathrm{v})=\left((\mathrm{x}, \mathrm{y})^{\prime}+(\mathrm{u}, \mathrm{v})^{\prime}\right)^{\prime}$ and + is the usual point in addition and $\left((x, y)^{\prime}=(4-x, 4-y)\right)$ :

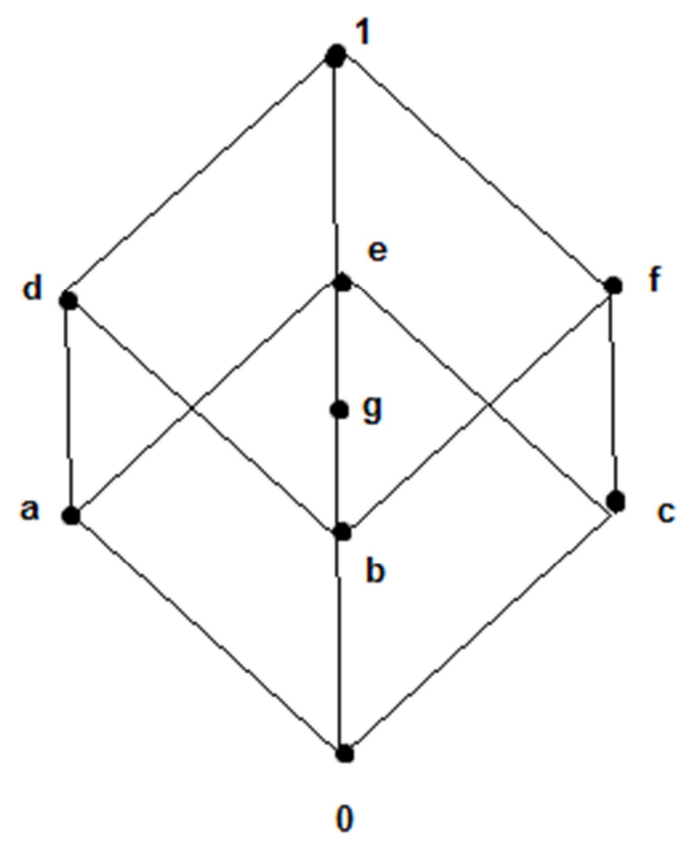

Figure 2. D-effect algebra.

Table 5. Show that $E \backslash\{g\}$ is a block of the assigned weak D-basic algebra $D B(E, \Pi)$

\begin{tabular}{lllllllllll}
\hline$\Delta$ & $\mathbf{0}$ & $\mathbf{A}$ & $\mathbf{b}$ & $\mathbf{C}$ & $\mathbf{d}$ & $\mathbf{e}$ & $\mathbf{f}$ & $\mathbf{g}$ & $\mathbf{1}$ & $\neg$ \\
\hline 0 & 0 & 0 & 0 & 0 & 0 & 0 & 0 & 0 & 0 & 1 \\
$\mathrm{a}$ & 0 & $\mathrm{a}$ & 0 & 0 & $\mathrm{a}$ & $\mathrm{a}$ & 0 & $\mathrm{~b}$ & $\mathrm{a}$ & $\mathrm{f}$ \\
$\mathrm{b}$ & 0 & 0 & 0 & 0 & $\mathrm{~b}$ & 0 & $\mathrm{~b}$ & 0 & $\mathrm{~b}$ & $\mathrm{e}$ \\
$\mathrm{c}$ & 0 & 0 & 0 & $\mathrm{C}$ & 0 & $\mathrm{c}$ & $\mathrm{c}$ & $\mathrm{b}$ & $\mathrm{c}$ & $\mathrm{d}$ \\
$\mathrm{d}$ & 0 & $\mathrm{~A}$ & $\mathrm{~b}$ & 0 & $\mathrm{~d}$ & $\mathrm{a}$ & $\mathrm{b}$ & $\mathrm{g}$ & $\mathrm{d}$ & $\mathrm{c}$ \\
$\mathrm{e}$ & 0 & $\mathrm{~A}$ & 0 & $\mathrm{C}$ & $\mathrm{a}$ & $\mathrm{g}$ & $\mathrm{c}$ & $\mathrm{b}$ & $\mathrm{e}$ & $\mathrm{b}$ \\
$\mathrm{f}$ & 0 & 0 & $\mathrm{~b}$ & $\mathrm{C}$ & $\mathrm{b}$ & $\mathrm{c}$ & $\mathrm{f}$ & $\mathrm{b}$ & $\mathrm{f}$ & $\mathrm{a}$ \\
$\mathrm{g}$ & 0 & $\mathrm{~A}$ & 0 & $\mathrm{C}$ & $\mathrm{a}$ & $\mathrm{b}$ & $\mathrm{b}$ & 0 & $\mathrm{~g}$ & $\mathrm{G}$ \\
$\mathrm{1}$ & 0 & $\mathrm{~A}$ & $\mathrm{~b}$ & $\mathrm{C}$ & $\mathrm{d}$ & $\mathrm{e}$ & $\mathrm{f}$ & $\mathrm{g}$ & 1 & 0 \\
\hline
\end{tabular}

It is obvious that $\mathrm{a} \leftrightarrow \mathrm{e}$, but $\mathrm{a}$ is not compatible with $\mathrm{g}=\mathrm{e}$ $\Delta$ e. Indeed, the only common lower bound of a, $g$ is 0 , and 0 $\nabla \mathrm{a}=\mathrm{f} \geq \mathrm{g}$ as well as $0 \nabla \mathrm{g}=\mathrm{g} \geq \mathrm{a}$, thus a $\leftrightarrow \mathrm{g}$ by (13).

In accordance with the conditions (12) and (14), we put $\mathrm{f} \sqcap \mathrm{e}=\mathrm{c}(=\mathrm{f} \Delta \mathrm{e})$ and $\mathrm{e} \Pi \mathrm{d}=\mathrm{a}(=\mathrm{e} \Delta \mathrm{d})$; in the other cases $\Pi$ coincides with inf. A direct inspection shows that $\mathrm{E} \backslash\{\mathrm{g}\}$ is a block of the assigned weak D-basic algebra $\mathrm{DB}(\mathrm{E}, \Pi)$ (see the table below (table 5.) which is closed under $\Pi$, but it is not closed under $\Delta$ as e $\Delta \mathrm{e}=\mathrm{g}$. On the other hand, $\{0, \mathrm{~b}$, e, $g, 1\}$ is both a block and a subalgebra of DB (E, $\Pi)$.

\section{References}

[1] Allam, A. A. E. M., Mikhaeel, N. N., \& Merdach, H. H. (2016). Commutative groupoid algebra. Journal of Mathematical and Computational Science, 6(2), 262.

[2] Chajda, I., and Länger, H.: "States on basic algebras." Mathematica Bohemica 142.2 (2017): 197-210.

[3] Chajda, I., Halas, R., Kuhr, J.: Every effect algebra can be made into a total algebra. Algebra universalis. 61(2): 139-150 (2009).

[4] Chajda, I., Lattices and semilattices having an antitone involution in every upper interval. Comment. Math. Univ. Carolin. 44(4): 577-585 (2003).

[5] Chajda, I., Halaš, R., Kuhr, J.: Many-valued quantum algebras. Algebra Universalis 60, 63-90 (2009).

[6] Chajda, I., Halaš, R., Kuhr, J.: Semilattice Structures. Heldermann, Lemgo (2007).

[7] Dvurečenskij, A., and Hyčko, M.: "Hyper effect algebras." Fuzzy Sets and Systems (2017).

[8] Foulis, D. J., Bennett, M. K.: Effect algebras and unsharp quantum logic. Found. Phys. 24, 1325-1346 (1994).

[9] Jezek, J., Quackenbush, R.: Directoids: algebraic models of up-directed sets. Algebra Universalis 27, 49-69 (1990).

[10] Kopka, F., Chovanec, F.: D-posets. Math. Slovaca 44, 21-34 (1994).

[11] Kühr, J., Chajda, I., and Halaš, R.: "The join of the variety of MV-algebras and the variety of orthomodular lattices." International Journal of Theoretical Physics 54. 12: 2244 2244(2015)

[12] Searle, SR., Khuri, AI.: Matrix algebra useful for statistics. John Wiley \& Sons; (2017).

[13] Stefan, F., Ronco, M., and Showers, P.: "Polytopes and algebras of grafted trees: Stellohedra." arXiv preprint arXiv: 1608.08546 (2016). 